\title{
Assessment of Serum Level of CXCL9 and CXCL10 in Cutaneous versus Systemic Lupus Erythematosus
}

\author{
Ghada Abd Elbadea Abd ElAziz Omar ${ }^{1}$ MD, Sabila Gomaa Mosa ${ }^{2}$ MD, Amal Abdel Aleem Morsy ${ }^{3}$ MD. \\ Radwa Osama Mohamed Kamel ${ }^{1, *}$ MD, Naglaa Mahmoud Hussein Ahmed Abdelaty ${ }^{1}$ MD.
}

* Corresponding Author:

Radwa Osama Mohamed Kamel

radwa.tirana@yahoo.com

Received for publication September 28, 2021; Accepted October 16, 2021; Published online October 16, 2021.

\section{Copyright The Authors published by Al-Azhar University, Faculty of Medicine, Cairo, Egypt. Users have the right to read, download, copy, distribute, print, search, or link to the full texts of articles under the following conditions: Creative Commons Attribution- Share Alike 4.0 International Public License (CC BY-SA 4.0). \\ doi: 10.21608/aimj.2021.98396.1586 \\ ${ }^{1}$ Dermatology and Venereology Department, Faculty of Medicine (for Girls), Al-Azhar University, Cairo, Egypt. \\ ${ }^{2}$ Internal Medicine Department Faculty of Medicine (for Girls), Al-Azhar University, Cairo, Egypt. \\ ${ }^{3}$ Clinical Pathology Department, Faculty of Medicine (for Girls), Al-Azhar University, Cairo, Egypt}

\begin{abstract}
Background: Lupus erythematosus has been a chronic inflammatory illness where chemokines plays a great role in its pathogenesis. CXCL9 and CXCL10 are chemokines which were researched in a variety of inflammatory skin disorders for their crucial role in immune responses. Aim of the study: : To compare CXCL9 and CXCL10 serum levels in patients suffering from cutaneous versus systemic lupus erythematosus. Patients and Methods: The forty-five Egyptian patients in this case control research were collected from the University Hospital's outpatient clinic between October 2018 and June 2019. Two groups of patients were established: DLE Group (Fifteen patients), and SLE group (Thirty patients) and forty control persons. Five $\mathrm{ml}$ of blood were obtained from all patients for assessment of serum CXCL9 and CXCL10 by enzmelinked immunosorbemt assay (ELISA) method.

Results: When comparing patients with DLE and SLE to controls, our findings demonstrated highly statistically considerable increases in CXCL9 and CXCL10 serum levels. Moreover, patients having SLE had a highly statistically considerable rise in both CXCL9 and CXCL10 serum levels when compared to DLE patients. Meanwhile, when comparing SLE patients having active disease to those having inactive disease, there was a statistically significant rise in CXCL9 and CXCL10 serum levels. Conclusion: The chemokines CXCL9 and CXCL10 may have had an etiopathogenesis role in SLE and DLE as they are increased in both DLE and SLE patients. In addition, CXCL10 levels in the serum could be used as a stand-alone biomarker for SLE activity.

Keywords: Systemic lupus erythematosis; discoid lupus erythematosus; CXCL9; CXCL10.
\end{abstract}

Disclosure: The authors have no financial interest to declare in relation to the content of this article. The Article Processing Charge was paid for by the authors.

Research Support: RCT approval numbers: NCT04656067 and PACTR202101794541918

Authorship: All authors have a substantial contribution to the article.

\section{INTRODUCTION}

Lupus erythematosus is a chronic autoimmune multisystem disorder ${ }^{1}$.The disease severity ranges from little cutaneous involvement to severe, potentially lethal systemic disease. Skin is the second most frequent organ involved with varying morbidity. $^{2}$

Cutaneous Lupus erythematosus (CLE) is a disfiguring, chronic skin condition that has a great influence on patients' quality of life. Cutaneous lesions are usually well-defined and present in areas that are exposed to the sun. Ultraviolet light can trigger or exacerbate the disease, which has a remitting and exacerbating course. ${ }^{3}$

DLE is the most prevalent subtype of $\mathrm{CCLE}^{4}$. About $25 \%$ of SLE patients have DLE-like lesions. They are presented as well-defind, erythematous, discoid plaques, with adherent scales and follicular plugging. Healing occur with thin, white atrophic noncontractile scar with slightly raised or hyperpigmented border. ${ }^{5}$

SLE is a chronic inflammatory autoimmune disease $^{6}$. Females are the ones that are most affected ( $~ 90 \%$ of cases), and is more prevalent in people of African descent? ${ }^{7}$. The etiology of SLE is multifactorial. The main Pathological features are: auto-antibodies overproduction secreted by overactive B lymphocytes, immune complexes deposition in target organs, increased proinflammatory cytokine production and T-lymphocyte defect. $^{\mathbf{8}, 9,10}$

CXCL9 and CXCL10, which are members of the CXC chemokine family ${ }^{11}$, were discovered to be 
overexpressed in the sera and/or tissues of patients with autoimmune disorders such as SLE ${ }^{\mathbf{1 2}}$. In patients with SLE, the CXCR3 ligands CXCL9 and CXCL10 were demonstrated to be the most significantly upregulated genes. ${ }^{13}$

\section{PATIENTS AND METHODS}

This case control study comprised 45 patients who were split into two groups based on clinical characteristics: the DLE group (15 patients) and the SLE group (30 patients). A control group of forty age-and gender-matched, apparently healthy individuals was also included. All patients were recruited from the University Hospital's Dermatology and Venereology outpatient clinic between October 2018 and June 2019. Before participating in this study, the subjects gave their informed written consent. The faculty of medicine's research ethics committee approved the study.

The study participants were of both sexes, aged between 20-50 years. Patients of other co-morbidities (systemic or dermatological diseases), other autoimmune diseases, drug induced lupus or Pregnancy and lactation were excluded.

A full medical history was taken for all patients, a complete general examination to detect systemic manifestations of LE, a dermatological examination including distribution, morphology, extent and severity of skin lesions, and measuring disease activity using CLASI score in the DLE group Figure $1^{14}$ and SLEDAI score in SLE group.

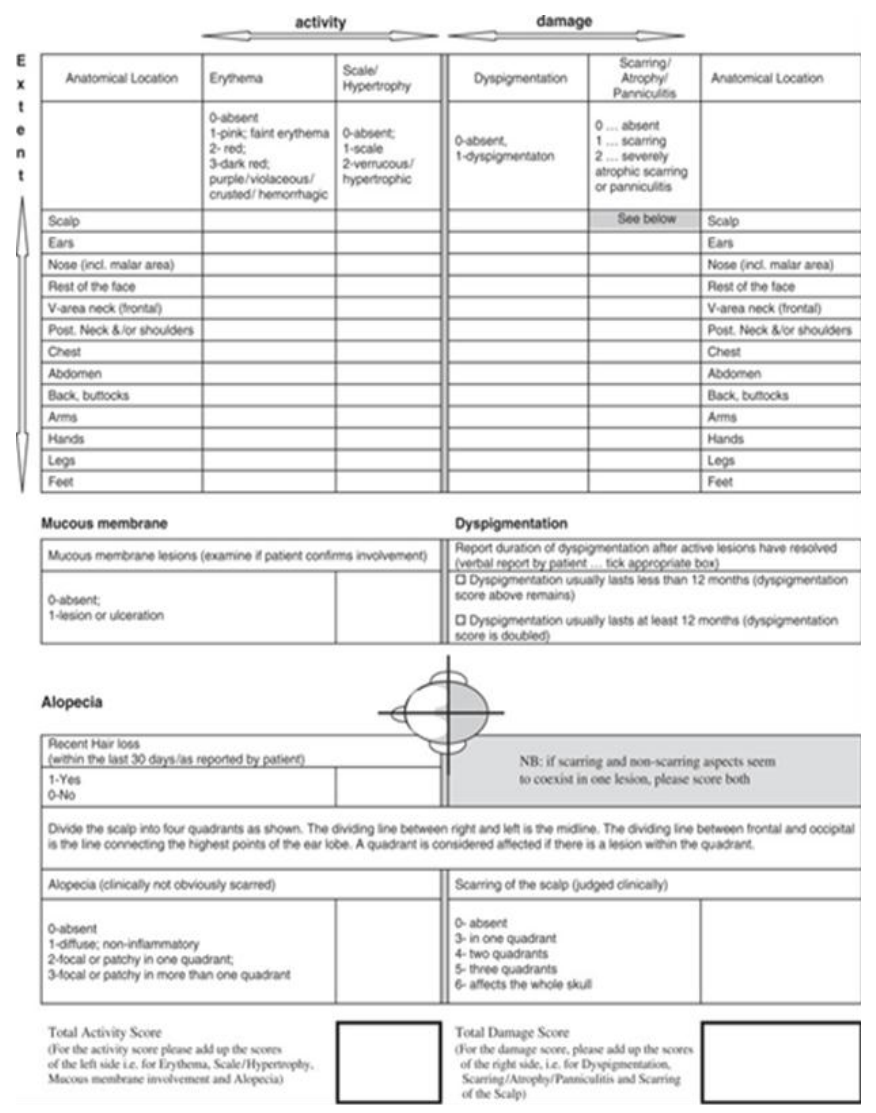

Fig. 1: Cutaneous Lupus Erythematosus Disease Area and Severity Index (CLASI).
Two scores make up the CLASI: one that describes the disease's activity and another that measures the disease's damage. Dyspigmentation and scarring, as well as scarring alopecia, are used to assess damage ${ }^{14}$.

CLASI revealed that activity scores were significantly determined by the amount of erythema ${ }^{15}$. The total activity score is composed of the following components: redness degree $(0-3)$ and scale (0-2), involvement of mucous membrane $(0-1)$, recent loss of hair (0-1), and non- scarring alopecia $(0-3)$. The total damage score consists of the following components: the dyspigmentation degree $(0-2)$ and scarring (0-2), the dyspigmentation persistence for more than twelve months, double the dyspigmentation score, and scalp scarring $(0,3,4,5$, $6)^{14}$.

SLEDAI is a list of 24 elements, 16 of which are clinical elements and 8 are laboratory data. The presence or absence of these symptoms in the preceding 10 days is used to score these items ${ }^{16}$.

Following the evaluation of each item, a score is computed by adding the scores assigned to every item, depending on its individual weights. The involvement of organs has been weighed as follows: pain in joints or renal disease is multiplied by four, whereas neurological involvement of the central nervous system is multiplied by eight. The ultimate score runs from 0 and 105. The greater the score, the more significant the disease activity. Scores of 6 and higher are regarded to be indicative of active disease that necessitates treatment. Scores of more than 20 are, however, extremely rare. Clinically important changes include those with a score of 6 (improving) and 8 (worsening) ${ }^{17}$.

Five to seven $\mathrm{ml}$ of blood was collected from all studied groups by venipuncture under aseptic condition. Samples were collected into a serum separator tube. Samples were centrifuged for $15 \mathrm{~min}$ after clot formation. The serum has been removed, and the samples have been kept at $5 \sim 20{ }^{\circ} \mathrm{C}$ until analysis. CXCL9 and CXCLI0 serum concentrations were assayed via ELISA utilizing a commercially accessible kit (R \& D Systems, Inc. 614 McKinley "Place NE, Minneapolis, MN 55413, USA. E-MAIL: info@RnDSystems.com).

\section{Statistical Analysis}

The Statistical Package for the Social Sciences (SPSS/version 2000) program has been utilized to analyze the data.

\section{RESULTS}

This case control study comprised forty five Egyptian patients who were split into two groups, the DLE group (15 patients) and the SLE group (30 patients). The DLE group age ranged from 20-49 years (mean $38.87 \pm 8.42 \mathrm{SD}$ ). They were 8 females (53.3\%) and 7 male (46.7\%). The SLE group age ranged from 20-49 years (mean 34.77 $\pm 9.95 \mathrm{SD}$ ). They were 23 females $(76.7 \%)$ and 7 males $(23.3 \%)$. In addition, the study included forty healthy gender and age matched volunteers who acted as controls. 
Their ages ranged from $21-49$ (mean of $32.83 \pm 7.41$ SD) they were 29 females $(71.5 \%)$ and 11 males $(27.5 \%)$.

The mean disease duration in DLE patients was $(13.00 \pm 6.01 \mathrm{SD})$, ranging from 4 to 22 years. The mean onset age was 11.7 years (median 12.5 range 217). 7 patients ( 46.7 percent) had a positive family history, while 8 patients had a negative family history (53.3 percent). Five patients (33.3 percent) were DLE active and 10 patients (66.7 percent) were DLE inactive based on CLASI score.

The disease duration for SLE varied from 1 year to 23 years, with a mean of $(9.97 \pm 6.92 \mathrm{SD})$. The mean onset age was 16.7 years (median 15.5 range 13.2 18 y). 6 patients $(20 \%)$ had a positive family history, whereas $24(80 \%)$ had a negative one. Twenty patients $(66.7 \%)$ were SLE active and 10 patients $(33.3 \%)$ were SLE inactive based on SLEDAI score.

When it came to CXCL9 and CXCL10 serum levels, there were highly statistically significant differences between the DLE and control groups ( $\mathrm{p}$-value = 0.000) (Table 1).
There were also highly statistically significant differences in serum levels of CXCL9 and CXCL10 between the SLE and control groups ( $\mathrm{p}$-value = 0.000) (Table 2).

There were highly statistically significant differences in serum CXCL9 and CXCL10 levels between the DLE and SLE groups $(\mathrm{p}$-value $=0.000)($ Table 3$)$.

In all cases, there was no significant connection between serum CXCL9 and CXCL10 levels, age, or disease duration (Table 4).

There was no statistically significant relation between serum CXCL9 and CXCL10 levels and disease activity in the DLE group (Table 5).

There were a highly statistically significant and statistically significant relations between serum level of CXCL9 and CXCL10, respectively in SLE group regarding disease activity with $(\mathrm{P}$-value $=0.002$ and p-value $=0.019)($ Table 6$)$.

\begin{tabular}{|c|c|c|c|c|c|c|}
\hline & & DLE group & Control group & \multirow[t]{2}{*}{ Test value } & \multirow[t]{2}{*}{ P-value } & \multirow[t]{2}{*}{ Sig. } \\
\hline & & No. $=15$ & No. $=40$ & & & \\
\hline \multirow{2}{*}{$\begin{array}{r}\text { CXCL9 } \\
(\mathrm{pg} / \mathrm{ml})\end{array}$} & Mean \pm SD & $4.87 \pm 1.03$ & $26.63 \pm 6.09$ & \multirow[t]{2}{*}{$-22.117 \bullet$} & \multirow[t]{2}{*}{0.000} & \multirow[t]{2}{*}{ HS } \\
\hline & Range & $3.5-7.5$ & $18.4-36.7$ & & & \\
\hline \multirow{2}{*}{$\begin{array}{c}\text { CXCL10 } \\
(\mathrm{pg} / \mathrm{ml})\end{array}$} & Mean \pm SD & $3.18 \pm 1.05$ & $16.95 \pm 2.46$ & \multirow[t]{2}{*}{$-29.252 \bullet$} & \multirow[t]{2}{*}{0.000} & \multirow[t]{2}{*}{ HS } \\
\hline & Range & $2-7$ & $12.6-22.4$ & & & \\
\hline
\end{tabular}

Table 1: Comparison between the DLE group and the controls in terms of CXCL9 and CXCL10.

\begin{tabular}{ccccccc}
\hline & & SLE group & Control group & Test value & P-value & Sig. \\
\cline { 2 - 4 } & & No. $=\mathbf{3 0}$ & No. $=\mathbf{4 0}$ & & & \\
CXCL9 & Mean \pm SD & $4.87 \pm 1.03$ & $45.03 \pm 6.78$ & \multirow{2}{*}{37.011} & 0.000 & HS \\
$(\mathbf{p g} / \mathbf{m l})$ & Range & $3.5-7.5$ & $22.2-58.8$ & & & \\
CXCL10 & Mean \pm SD & $3.18 \pm 1.05$ & $20.98 \pm 3.62$ & $-29.541 \bullet$ & 0.000 & HS \\
$(\mathbf{p g} / \mathbf{m l})$ & Range & $2-7$ & $15.5-27.5$ & & & \\
\hline
\end{tabular}

Table 2: Comparison between the SLE group and controls in terms of serum CXCL9 and CXCL10 levels.

\begin{tabular}{rcccccc}
\hline & & DLE group & SLE group & Test & P-value & Sig. \\
\cline { 3 - 4 } & & No. $=\mathbf{1 5}$ & No. $=\mathbf{3 0}$ & value & & \\
CXCL9 $(\mathbf{p g} / \mathrm{ml})$ & Mean $\pm \mathrm{SD}$ & $26.63 \pm 6.09$ & $45.03 \pm 6.78$ & $-8.870 \bullet$ & 0.000 & HS \\
& Range & $18.4-36.7$ & $22.2-58.8$ & & & \\
CXCL10 $(\mathbf{p g} / \mathrm{ml})$ & Mean $\pm \mathrm{SD}$ & $16.95 \pm 2.46$ & $20.98 \pm 3.62$ & $-3.880 \bullet$ & 0.000 & HS \\
& Range & $12.6-22.4$ & $15.5-27.5$ & & & \\
\hline
\end{tabular}

Table 3: Comparison between the DLE group and the SLE group in terms of serum CXCL9 and CXCL10 levels.

\begin{tabular}{ccccc}
\hline & \multicolumn{4}{c}{ All cases } \\
\cline { 2 - 5 } & \multicolumn{3}{c}{ CXCL9 } & \multicolumn{2}{c}{ CXCL10 } \\
CXCL9 (pg/ml) & r & P-value & r & P-value \\
CXCL10 (pg/ml) & - & - & $0.675^{* *}$ & 0.000 \\
Age (yrs) & $0.675^{* *}$ & 0.000 & - & - \\
Disease Duration (yrs) & -0.243 & 0.108 & -0.174 & 0.254 \\
\hline
\end{tabular}

Table 4: Connection between serum CXCL9 and CXCL10 levels with age and duration in all cases. 


\begin{tabular}{|c|c|c|c|c|c|c|}
\hline \multicolumn{2}{|c|}{ DLE group } & \multicolumn{2}{|c|}{ CXCL9 } & \multirow{4}{*}{$\begin{array}{c}\text { Test } \\
\text { value } \\
1.688 \neq\end{array}$} & \multirow{4}{*}{$\begin{array}{c}\text { P-value } \\
0.115\end{array}$} & \multirow[t]{2}{*}{ Sig. } \\
\hline \multirow{3}{*}{$\begin{array}{l}\text { Disease activity } \\
\text { (CLASI score) }\end{array}$} & \multirow[b]{2}{*}{ Inactive } & Mean \pm SD & Range & & & \\
\hline & & $24.87 \pm 6.1$ & $18.4-36.7$ & & & NS \\
\hline & Active & $30.16 \pm 4.76$ & $21.8-33.7$ & & & \\
\hline \multicolumn{2}{|c|}{ DLE group } & \multicolumn{2}{|c|}{ CXCL10 } & \multirow{4}{*}{$\begin{array}{c}\text { Test } \\
\text { value } \\
0.316 \neq\end{array}$} & \multirow[t]{2}{*}{ P-value } & \multirow[t]{2}{*}{ Sig. } \\
\hline \multirow{3}{*}{$\begin{array}{r}\text { Disease activity } \\
\text { (CLASI score) }\end{array}$} & & Mean \pm SD & Range & & & \\
\hline & & $16.8 \pm 2.98$ & $12.6-22.4$ & & \multirow[t]{2}{*}{0.757} & \multirow[t]{2}{*}{ NS } \\
\hline & Active & $17.24 \pm 1.04$ & $15.9-18.3$ & & & \\
\hline \multicolumn{7}{|l|}{ Table 5: Relation } \\
\hline \multirow{2}{*}{\multicolumn{2}{|c|}{ SLE group }} & \multicolumn{2}{|c|}{ CXCL9 } & \multirow{4}{*}{$\begin{array}{c}\text { Test } \\
\text { value } \neq \\
3.467\end{array}$} & \multirow[t]{2}{*}{ P-value } & \multirow[t]{2}{*}{ Sig. } \\
\hline & & Mean \pm SD & Range & & & \\
\hline \multirow{2}{*}{$\begin{array}{l}\text { Disease activity } \\
\text { (SIEDAI score) }\end{array}$} & Inactive & $39.87 \pm 6.94$ & $22.2-47.1$ & & \multirow[t]{2}{*}{0.002} & \multirow[t]{2}{*}{ HS } \\
\hline & Active & $47.62 \pm 5.12$ & $36.4-58.8$ & & & \\
\hline \multirow[t]{2}{*}{ SLE group } & & \multicolumn{2}{|c|}{ CXCL10 } & \multirow{4}{*}{$\begin{array}{c}\text { Test } \\
\text { value } \neq \\
2.489\end{array}$} & \multirow[t]{2}{*}{ P-value } & \multirow[t]{2}{*}{ Sig. } \\
\hline & & Mean \pm SD & Range & & & \\
\hline \multirow{2}{*}{$\begin{array}{l}\text { Disease activity } \\
\text { (SLEDAI score) }\end{array}$} & Inactive & $18.84 \pm 3$ & $15.5-24.3$ & & 0.019 & $S$ \\
\hline & Active & $22.06 \pm 3.48$ & $18-27.5$ & & & \\
\hline
\end{tabular}

Table 6: Relation of serum level of CXCL9 and CXCL10 with disease activity in SLE group.

\section{DISCUSSION}

Systemic lupus erythematosus (SLE) is an autoimmune disease that causes inflammation of the organs. Its pathogenesis includes formation of pathogenic autoantibodies directed towards nucleic acids and the proteins that bind to them, indicating a complete loss of self-antigen recognition. The interaction between genetic susceptibility and environmental triggers results in tolerance loss and subsequent immunological dysregulation ${ }^{18}$. DLE is the most frequent type of (CCLE) ${ }^{19}$.

CXCL9 and CXCL10 have been linked to the development of inflammatory and autoimmune diseases. They are chemokines that belong to the CXC subfamily that attract activated $\mathrm{T}$ cells that express the CXCR 3 chemokine receptor. CXCL9 and CXCL10 have been shown to be important in Th1 and $\mathrm{Tc}$ cell recruitment and activation ${ }^{21}$.

The goal of this case control study was to evaluate serum CXCL9 and CXCL10 levels in CLE patients versus SLE patients.

Our findings revealed that serum CXCL9 and CXCL10 levels in DLE patients were considerably higher than in controls, significantly higher in SLE patients compared to controls, and significantly higher in SLE patients compared to DLE patients.

These results were consistent with Bauer et al. (2009) and Mikita et al. (2011) who observed an increased serum level of CXCL 9 and CXCL 10 in both DLE and SLE patients than in healthy control subjects ${ }^{22,23}$.

In human keratinocytes, IFN-gamma promoted the expression of various proinflammatory cytokines, notably CXCL9, that drive immune cell recruitment and have been related to the creation of CLE skin infections, according to Zahn et al. (2011) ${ }^{24}$.

Meller et al. (2005) identified that the CXCR3 ligands CXCL9, CXCL10, and CXCL11 are the most commonly expressed members of the chemokine family in CLE. The expression of such ligands is linked to the existence of a large inflammatory infiltrate constituted primarily of CXCR3-expressing cells, which include skin-homing lymphocytes and blood dendritic cell antigen 2-positive plasmacytoid dendritic cells ${ }^{25}$.

Moreover, Meller et al. (2005) reported that CXCL9 on superficial dermal plexus dendritic and endothelial cells, and also CXCL10 in the basal epidermis and perivascular leukocytes, recruits chemokine (CXC motif) receptor (CXCR) 3-positive effector cells ${ }^{25}$.

T-helper 1 chemokines (CXCL9, CXCL10, CXCL11 and CXCL12) are the most significantly increased chemokines in the whole chemokine family, and they're detected where dermis and epidermis injury is seen in $\mathrm{DLE}^{26}$. CXCR3, which promotes lesional keratinocytic cell death, most likely through keratinocyte necroptosis, is activated by these proinflammatory chemokines, which recruit cytotoxic type I immune cells to the lesions ${ }^{27}$.

Th1 cytokines, such as IFN- $\gamma$, promote expression of CXCR3 on lymphocytes and dendritic cells (DC) in lymphoid organs if an autoimmune response develops in SLE. These cells then gain the ability to move towards inflammatory chemokines (CXCL9, CXCL10, and CXCL11) generated by resident cells in the skin and kidneys (like fibroblasts). These cells (particularly Th1 cells) induce resident cells to boost chemokine synthesis through IFN- $\gamma$ secretion after being recruited from the blood in tissues which are inflammed ${ }^{13}$.

Moreover, Watanabe et al (2008) and Henneken et al (2005) reported an elevation in the ratio of CXCR3+ $B$ cells in SLE patients as well as an elevation in CXCL10 serum levels ${ }^{28,29}$.

In SLE and DLE, our results revealed no significant relationships among CXCL9 and CXCL10 regarding age or disease duration.

There was no significant relationship between CXCL9 and CXCL10 in DLE and disease activity, but there was a significant relationship between both CXCL9 and CXCL10 in SLE and disease activity.

This was in accordance with Bauer et al. (2009) who stated that CXCL10 and CXCL9 are elevated in SLE patients' sera, which could be linked to disease activity and contribute to the inflammatory condition. 
Furthermore, according to Bauer et al. (2009) and Kong et al. (2009) data, marked elevations of CXCL10 in the sera of SLE patients, the highest relationships with disease activity were found. So, CXCL10 was consistently the chemokine most significantly linked to present and future disease activity $^{22,30}$.

\section{CONCLUSION}

Based on our results, the chemokines CXCL9 and CXCL10 may have a role in the etiopathogenesis of SLE and DLE as they are increased in both DLE and SLE patients. In addition, serum CXCL10 levels could be used as a standalone biomarker for SLE activity.

\section{REFERENCES}

1. Pandya S, Falk H, Gerd RB, et al. The multifaceted balance of TNF- $\alpha$ and type I/II interferon responses in SLE and RA: how monocytes manage the impact of cytokines. J Mol Med. 2017; 5(6): 154-62.

2. Goodfield M, Dutz J and McCourt C. Lupus erythematosus. Rook's Textbook of Dermatology, Ninth Edition. 2016; 1-52.

3. Kuhn A and Landmann A. The classification and diagnosis of cutaneous lupus erythematosus. $J$. of Autoimmunity. 2014; 48-49: 14-9.

4. Holt AP, Haughton EL and Lalor PF, et al. Liver myofibroblasts regulate infiltration and positioning of lymphocytes in human liver. Gastroenterology. 2017; 136(2): 705-14.

5. Mahieu M, Yount $\mathrm{S}$ and Ramsey-Goldman R. Patient-reported outcomes in systemic lupus erythematosus. Rheumatic Disease Clinics. 2016; 42(2): 253-63.

6. Stojan G and Petri M: Epidemiology of systemic lupus erythematosus: An update. Curr Opin Rheumatol.2018; 30: 144- 50 .

7. Hiraki LT, Feldman $\mathrm{CH}$ and Liu J et al. Prevalence, incidence, and demographics of systemic lupus erythematosus and lupus nephritis from 2000 to 2004 among children in the US medicaid beneficiary population. Arthritis Rheum. 2012; 64: 2669-76.

8. Ghodke-Puranik $\mathrm{Y}$ and Niewold TB: Immunogenetics of systemic lupus erythematosus: A comprehensive review. J Autoimmun.2015; 64: $125-36$.

9. Quintero OL, Amador- Patarroyo MJ and Montoya- Ortiz G,et al. Autoimmune disease and gender: Plausible mechanisms for the female predominance of autoimmunity. J Autoimmun.2012; 38: J109- J19.

10. Barbhaiya M and Costenbader KH. Environmental exposures and the development of systemic lupus erythematosus. Curr Opin Rheumatol.2016; 28: 497- 505.

11. Kotrych D, Dziedziejko V and Safranow K,et al. Lack of association between CXCL9 and CXCL10 gene polymorphisms and the outcome of rheumatoid arthritis treatment with methotrexate. European Review for Medical and Pharmacological Sciences. 2015; 19(16): 3037-40.

12. Lee EY, Lee ZH and Song YW. The interaction between CXCL10 and cytokines in chronic inflammatory arthritis. Autoimmunity Reviews. 2013; 12: $554-7$.

13. Lacotte D, Brun S and Muller S, et al. CXCR3, Inflammation, and Autoimmune Diseases. Ann. N.Y. Acad. Sci. 2009; 1173: 310-7.

14. Albrecht J, Taylor L and Berlin JA, et al. The CLASI (Cutaneous Lupus Erythematosus Disease Area and Severity Index): an outcome instrument for cutaneous lupus erythematosus. J. Invest Dermatology. 2005; 125(5): 889-94.

15. Albrecht J and Werth VP. Development of the CLASI as an outcome instrument for cutaneous lupus erythematosus. Dermatol Ther. 2007; 20(2): 93-101.

16. Katz RS. Lupus Society of Illinois. https: //www.lupusil.org/ lupus-update-with-dr-katz.html. 2015.

17. Touma Z, Urowitz MB and Taghavi-Zadeh S, et al. Systemic lupus erythematosus disease activity Index 2000 Responder Index 50: sensitivity to response at 6 and 12 months. Rheumatology (Oxford). 2012; 51(10): 1814-9.

18. Choi J, Kim ST and Craft J. The Pathogenesis of Systemic Lupus Erythematosus - An Update Curr Opin Immunol. 2012; 24(6): 651-657.

19. Angel A, Vaillant J and Goyal A, et al. Systemic Lupus Erythematosus. StatPearls - NCBI Bookshelf.html. 2021.

20. van den Borne P, Quax PHA, Hoefer IE, et al. The Multifaceted Functions of CXCL10 in Cardiovascular Disease, BioMed Research International. 2014; Article ID 893106, 11 pages.

21. Villarroel L, Massardo L, Martínez ME, et al. Survival of Chilean patients with systemic lupus erythematosus. Semin Arthritis Rheum. 2014; 24(1): $1-11$.

22. Bauer JW, Petri M, Batliwalla FM , et al. Interferon regulated chemokines as biomarkers of systemic lupus erythematosus disease activity: a validation study, Arthritis and Rheumatism. 2009; 60(10): 3098-107.

23. Mikita N, Ikeda T, Ishiguro M, et al. Recent advances in cytokines in cutaneous and systemic lupus erythematosus. J Dermatol. 2011; 38(9):83949.

24. Zahn S, Rehkämper C, Kümmerer BM, et al. Evidence for a pathophysiological role of keratinocyte-derived type III interferon (IFN $\lambda$ ) in cutaneous lupus erythematosus. J Invest Dermatol. 2011; 131(1):133-40.

25. Meller S, Winterberg F, Gilliet M, et al. Ultraviolet radiation-induced injury, chemokines, and leukocyte 
recruitment: An amplification cycle triggering cutaneous lupus erythematosus. Arthritis Rheum. 2005; 52(5):1504-16

26. Oke V and Wahren-Herlenius M. Cutaneous lupus erythematosus: clinical aspects and molecular pathogenesis. J Intern Med. 2013; 273(6):544-54.

27. Lauffer F, Jargosch M, Krause L, et al. Type I immune response induces keratinocyte necroptosis and is associated with interface dermatitis. $J$ Invest Dermatol. 2018; 138(8):1785-94.

28. Henneken M, Dörner T, Burmester GR, et al. Differential expression of chemokine receptors on peripheral blood B cells from patients with rheumatoid arthritis and systemic lupus erythematosus. Arthritis Res Ther. 2005; 7(5):R100113.

29. Watanabe T, Suzuki J, Mitsuo A, et al. Striking alteration of some populations of T/B cells in systemic lupus erythematosus: relationship to expression of CD62L or some chemokine receptors. Lupus. 2008; 17(1):26-33.

30. Kong KO, Tan AW, Thong BY, et al. Enhanced expression of interferon-inducible protein-10 correlates with disease activity and clinical manifestations in systemic lupus erythematosus. Clin Exp Immunol. 2009; 156(1):134-40 